\title{
The influence of age on health valuations: the older olds prefer functional independence while the younger olds prefer less morbidity
}

This article was published in the following Dove Press journal:

Clinical Interventions in Aging

8 July 2015

Number of times this article has been viewed

\author{
Cynthia S Hofman ${ }^{1,2}$ \\ Peter Makai \\ Han Boter ${ }^{3}$ \\ Bianca M Buurman ${ }^{4}$ \\ Anton J de Craen ${ }^{5}$ \\ Marcel GM Olde Rikkert' \\ Rogier Donders ${ }^{2}$ \\ René JF Melis' \\ 'Department of Geriatric Medicine, \\ Radboud University Medical Center, \\ Nijmegen, the Netherlands; \\ ${ }^{2}$ Department for Health Evidence, \\ Radboud University Medical Center, \\ Nijmegen, the Netherlands; \\ ${ }^{3}$ Department of Epidemiology, \\ University of Groningen, University \\ Medical Centre Groningen, \\ Groningen, the Netherlands; \\ ${ }^{4}$ Department of Internal Medicine, \\ Section of Geriatric Medicine, \\ Academic Medical Center, Amsterdam, \\ the Netherlands; ${ }^{5}$ Department of \\ Gerontology and Geriatrics, Leiden \\ University Medical Centre, Leiden, \\ the Netherlands
}

Background: To assess the effectiveness of geriatric interventions, The Older Persons and Informal Caregivers Survey - Composite Endpoint (TOPICS-CEP) has been developed based on health valuations of older persons and informal caregivers. This study explored the influence of the raters' age on the preference weights of TOPICS-CEP's components.

Methods: A vignette study was conducted with 200 raters (mean age \pm standard deviation: $72.5 \pm 11.8$ years; $66.5 \%$ female). Profiles of older persons were used to obtain the preference weights for all TOPICS-CEP components: morbidity, functional limitations, emotional wellbeing, pain experience, cognitive functioning, social functioning, self-perceived health, and self-perceived quality of life. The raters assessed the general wellbeing of these vignettes on a $0-10$ scale. Mixed linear regression analysis with interaction terms was used to explore the effects of raters' age on the preference weights.

Results: Interaction effects between age and the TOPICS-CEP components showed that older raters gave significantly $(P<0.05)$ more weight to functional limitations and social functioning and less to morbidities and pain experience, compared to younger raters.

Conclusion: Researchers examining effectiveness in elderly care need to consider the discrepancies between health valuations of younger olds and older olds when selecting or establishing outcome measures. In clinical decision making, health care professionals need to be aware of this discrepancy as well. For this reason we highly recommend shared decision making in geriatric care.

Keywords: general wellbeing, preferences, valuation, domains, composite endpoint, age

\section{Introduction}

Comparing intervention outcomes for older persons is challenging because their health states are complex, with problems on multiple health domains, and because interventions often target a broad range of these domains. ${ }^{1}$ However, comparative effectiveness research in geriatric care becomes more straightforward when clinically important outcome parameters are combined into a multidimensional preference-weighted outcome measure. Such a composite endpoint (CEP) can efficiently deal with the issue of multiplicity, eg, if more than one outcome is important for effectiveness evaluation or if an intervention has the potential to improve more than one health domain. By using a preference-weighted multifaceted outcome measure, the relative importance of the various outcomes is taken into account.

A CEP is of particular interest for The Older Persons and Informal Caregivers Survey Minimum Data Set (TOPICS-MDS), a data repository containing data from 41 research projects participating in the Dutch National Care for the Elderly Program. ${ }^{2}$ To promote comparability between these research studies, a preference-weighted
Correspondence: Cynthia Hofman Department of Geriatric Medicine (HP 925), Radboud University Medical Center, PO Box 9101, $6500 \mathrm{HB}$, Nijmegen, the Netherlands $\mathrm{Tel}+3 \mid 615169663$ Email cynthia.hofman@radboudumc.nl 
CEP for the TOPICS-MDS for care receivers (referred to as TOPICS-CEP) was established by means of a vignette study and based on the health-state valuations of older persons and informal caregivers. ${ }^{3}$

Briefly, TOPICS-CEP is a preference-weighted index ranging from 0 (worst possible general wellbeing) to 10 (best possible general wellbeing). It combines 42 data points from TOPICS-MDS covered by eight components: morbidities (a list of 17 predefined conditions used in the Netherlands), ${ }^{4}$ functional limitations (Katz index of independence), ${ }^{5}$ emotional wellbeing (mental health subscale of the RAND-36), ${ }^{6}$ pain experience (pain dimension of the EQ-5D), ${ }^{7}$ cognitive problems (cognition dimension of the EQ-5D+C), ${ }^{7}$ social functioning (item 10 from the RAND-36), ${ }^{6}$ self-perceived health (item 1 from the RAND-36), ${ }^{6}$ self-perceived quality of life (QOL) (phrasing similar to the self-perceived health item from the RAND-36). The data points included in TOPICSCEP regard all the variables (or items) from TOPICS-MDS for older persons that carry information relevant for understanding an individual's outcome. This excludes demographics and health service utilization. Excluding these components was based on the rationale that demographics such as sex and age and health service utilization cannot be influenced by health care delivery. An overview of the components, their preference weights, items, and levels can be found in Table S1. More detailed information about the development of TOPICS-CEP can be found elsewhere., ${ }^{3,8}$

Previous research has shown that variation in health-state preferences is influenced by various characteristics such as sex, age, and current health. ${ }^{9-13}$ This variability means that the value of a particular health status depends on who served as participants when evaluating the various health states. The variability can be explained by, eg, one's reference point, perspective, and coping strategies. TOPICS-CEP was established based on the health-state preferences of a heterogeneous group of raters. Results from our previous study indicated that the preference weights of older persons and informal caregivers were not significantly different. ${ }^{3}$

This study aimed: 1) to explore whether the age of our raters systematically influenced the preference weights of TOPICS-CEP components, and 2) to examine how agebased preference weights affected TOPICS-CEP scores. The framework we used can be found in Figure 1.

\section{Methods}

\section{Ethical approval}

The Medical Ethics Committee of the Radboud University Medical Center formally stated that this study was exempt from ethical review (Radboud University Medical Center Ethical Committee review reference number: CMO: 2010/244).

\section{Study design}

A vignette study was conducted to obtain the preference weights for the eight TOPICS-CEP components: morbidities, functional limitations, emotional wellbeing, pain experience, cognitive problems, social functioning, self-perceived health, and self-perceived QOL. The participants rated the general wellbeing (GWB) of case vignettes, which were short descriptions or profiles of older persons.

\section{Participants}

Two hundred persons who mastered the Dutch language sufficiently participated as raters. They were recruited and the data were collected at four academic centers (Radboud University Medical Center, University Medical Centre Groningen, Academic Medical Center, and Leiden University Medical Centre) spread over the Netherlands, covering both urban and more-rural parts of the country. All participants provided written informed consent.

\section{Material}

In total, 292 different versions of the same basic vignette (same items) were constructed to obtain a wide spectrum of health states. The vignettes were based on data of a sample of cases derived from the TOPICS-MDS national database, which consists of pooled data from various research projects that differ across study design, sampling framework, and inclusion criteria. By using empirical data, only vignettes with plausible health states were constructed. In general, each vignette included 46 items covering the eight previously described TOPICS-CEP components.

\section{Procedure}

The vignette study was conducted in an environment familiar to the participant, eg, in their own home or community center, in their living area. To collect information about rater characteristics, participants were first asked to fill in the TOPICS-MDS themselves; the participants who did not provide informal care to anyone filled in the TOPICS-MDS for care receivers and the informal caregivers filled in the TOPICS-MDS for caregivers. ${ }^{14,15}$ Then, the participants were asked to assess the GWB of two trial cases (which were the same for every participant) and ten randomly assigned cases on a $0-10$ scale (worst to best). The participants were allowed to use one decimal; this scale is in line with the Dutch grading system and was therefore well known to our participants. 


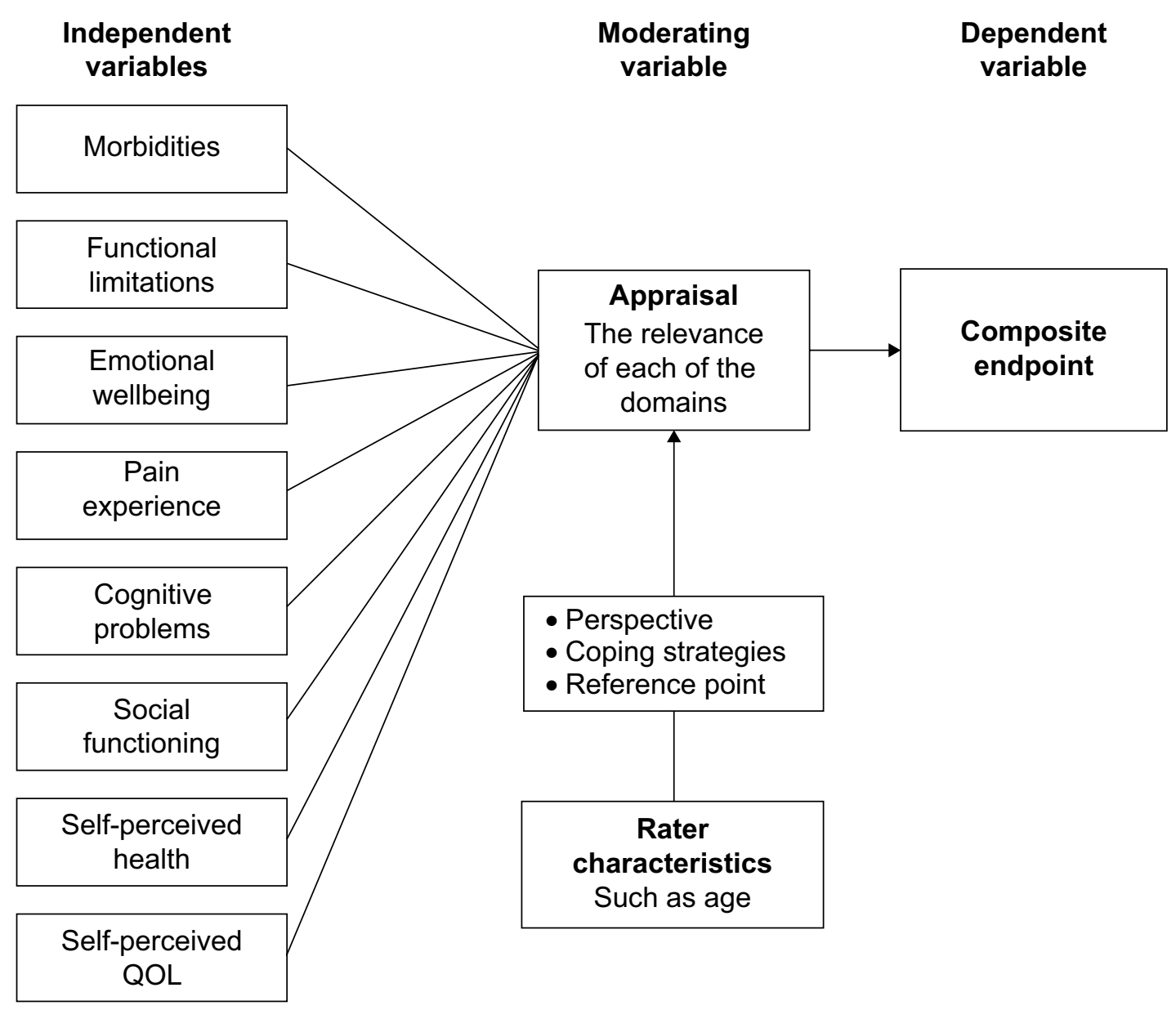

Figure I Study framework.

Note: Framework: combining eight components into one generic composite endpoint (TOPICS-CEP) and the influence of rater characteristics.

Abbreviations: QOL, quality of life; TOPICS-CEP, The Older Persons and Informal Caregivers Survey - Composite Endpoint index.

\section{Statistical analyses}

Mixed linear regression analysis was used to study the influence of the raters' age on the TOPICS-CEP preference weights. The model had the following structure: 1) the GWB scores were used as the dependent variable; 2) the eight CEP components were used as independent variables; 3 ) to correct for clustering within raters, a random (rater dependent) intercept was included; and 4) the factor age was included in the model together with the interaction terms with each of the CEP components (eg, age $\times$ morbidities). The parameter estimates (unstandardized coefficients) for the eight components represent the preference weights. We examined how age-based preference weights would affect TOPICS-CEP scores of our vignette cases by means of a paired-sample $t$-test and a Bland-Altman plot.

\section{Results}

The mean age \pm standard deviation (SD) of the 200 raters was $72.5 \pm 11.8$ years.

\section{Does age influence TOPICS-CEP's preference weights?}

The interaction effects between age and TOPICS-CEP components morbidities, functional limitations, pain experience, social functioning, and self-perceived health, respectively, were found to be significant $(P<0.05)$ (Table 1$)$. On average, the older raters gave significantly $(P<0.05)$ more weight to functional limitations and social functioning and less to morbidities and pain experience, in comparison to younger raters.

\section{Does age affect TOPICS-CEP scores?}

Based on our findings, we constructed a model that represented the health-state preferences of 65-year-old persons (TOPICS-CEP-65) and a model that represented those of 85-year-old persons (TOPICS-CEP-85), the older olds (Table 2). These models showed that on average the TOPICSCEP-65 score decreased by 0.15 points per additional disease present in a vignette case, while the TOPICS-CEP-85 score 
Table I Linear mixed models with interaction terms between the raters' age and each of the TOPICS-CEP components

\begin{tabular}{|c|c|c|c|c|}
\hline \multirow[b]{2}{*}{ Intercept } & \multirow{2}{*}{$\begin{array}{l}\text { Estimates } \\
9.03\end{array}$} & \multicolumn{2}{|c|}{$95 \%$ confidence limits } & \multirow{2}{*}{$\begin{array}{l}\boldsymbol{P} \text {-value } \\
0.00 * *\end{array}$} \\
\hline & & 7.66 & 10.40 & \\
\hline Age (centered) & -0.01 & -0.03 & 0.00 & 0.07 \\
\hline Morbidities & -0.14 & -0.15 & -0.12 & $0.00 * *$ \\
\hline Functional limitations & -0.12 & -0.13 & -0.11 & $0.00 * *$ \\
\hline Emotional wellbeing & -0.03 & -0.04 & -0.03 & $0.00 * *$ \\
\hline Pain experience & -0.05 & -0.11 & 0.02 & 0.16 \\
\hline Cognitive problems & -0.14 & -0.22 & -0.05 & $0.00 * *$ \\
\hline Social functioning & 0.01 & -0.02 & 0.04 & 0.60 \\
\hline Self-perceived health & -0.16 & -0.20 & -0.12 & $0.00 * *$ \\
\hline Self-perceived QOL & -0.02 & -0.07 & 0.02 & 0.33 \\
\hline Morbidities $\times$ raters' age & 0.00 & 0.00 & 0.00 & $0.05^{*}$ \\
\hline Functional limitations $\times$ raters' age & 0.00 & 0.00 & 0.00 & $0.04^{*}$ \\
\hline Emotional wellbeing $\times$ raters' age & 0.00 & 0.00 & 0.00 & 0.42 \\
\hline Pain experience $\times$ raters' age & 0.01 & 0.00 & 0.01 & $0.02 *$ \\
\hline Cognitive problems $\times$ raters' age & 0.00 & -0.01 & 0.01 & 0.88 \\
\hline Social functioning $\times$ raters' age & 0.00 & -0.01 & 0.00 & $0.05^{*}$ \\
\hline Self-perceived health $\times$ raters' age & 0.00 & -0.01 & 0.00 & 0.07 \\
\hline Self-perceived QOL $\times$ raters' age & 0.00 & 0.00 & 0.01 & 0.14 \\
\hline
\end{tabular}

Notes: Dependent variable: general wellbeing score; $* P<0.05 ; * * P<0.0$ I.

Abbreviations: QOL, quality of life; TOPICS-CEP, The Older Persons and Informal Caregivers Survey - Composite Endpoint index.

decreased by 0.12 points. Thus, the component morbidities had a larger negative impact on the GWB scores given to the vignettes by younger persons than those given by older persons. The same applies for the component pain experience (0.09 versus 0.03$)$. In contrast, the models showed that on average the TOPICS-CEP- 65 scores decreased by 0.11 points per additional functional limitation, while TOPICS-CEP-85 scores decreased by 0.13 points. Hence, the component functional limitation has a smaller negative impact on the GWB scores given to the vignettes by younger persons than those given by older persons. The same applies for the component social functioning ( 0.03 versus -0.03 ).

Of the 292 cases described in the vignettes, the majority ( $96.6 \%, \mathrm{n}=282)$ had no missing data points for the calculation

Table 2 TOPICS-CEP models based on the health state preferences of 65-year-old versus 85 -year-old persons

\begin{tabular}{lll}
\hline & TOPICS-CEP-65 & TOPICS-CEP-85 \\
\hline Intercept & 9.14 & 8.85 \\
Morbidities & -0.15 & -0.12 \\
Functional limitations & -0.11 & -0.13 \\
Emotional wellbeing & -0.04 & -0.03 \\
Pain experience & -0.09 & 0.03 \\
Cognitive problems & -0.13 & -0.14 \\
Social functioning & 0.03 & -0.03 \\
Self-perceived health & -0.14 & -0.20 \\
Self-perceived QOL & -0.05 & 0.02 \\
\hline
\end{tabular}

Abbreviations: QOL, quality of life; TOPICS-CEP-65, The Older Persons and Informal Caregivers Survey - Composite Endpoint scores for 65-year-old persons; TOPICS-CEP-85, The Older Persons and Informal Caregivers Survey - Composite Endpoint scores for 85 -year-old persons. of TOPICS-CEP scores. The minimum and maximum scores for the TOPICS-CEP-65 were 3.54 and 9.97, respectively, and were 3.36 and 9.90 for the TOPICS-CEP-85. Compared to TOPICS-CEP-65 scores (mean $\pm \mathrm{SD}=7.46 \pm 1.17$ ), the TOPICS-CEP-85 scores (mean $\pm \mathrm{SD}=7.57 \pm 1.23$ ) had a significantly higher mean (mean difference $\pm \mathrm{SD}=0.11 \pm 0.26$; $P<0.001)$. The two TOPICS-CEP scores were highly correlated $(r=0.98, P<0.001)$.

The Bland-Altman plot showed consistent variability and there was no trend visible across the graph (Figure 2). The average of TOPICS-CEP-65 and TOPICS-CEP-85 scores ranged from 3.48 to 9.93 (mean $\pm \mathrm{SD}=7.51 \pm 1.19$ ), and the difference between the scores ranged from -0.72 to 0.85 . The average bias was $-0.11 \pm 0.26$, and the limits of agreements were -0.63 and 0.41 .

\section{Discussion}

Our findings suggest that the preference weights of TOPICSCEP components derived in our previous study were influenced by our raters' age. On average, the older the rater 1) the greater the impact of functional limitations and social functioning was on the GWB scores given to the vignette cases; and 2 ) the smaller the impact of morbidities and pain experience was on the GWB scores given to the vignette cases.

Results of the paired-sample $t$-test suggest that age does have an effect on health state valuations. On average, TOPICS-CEP scores of the sample cases were higher when the preference weights of the older olds are used compared those used of younger olds. 


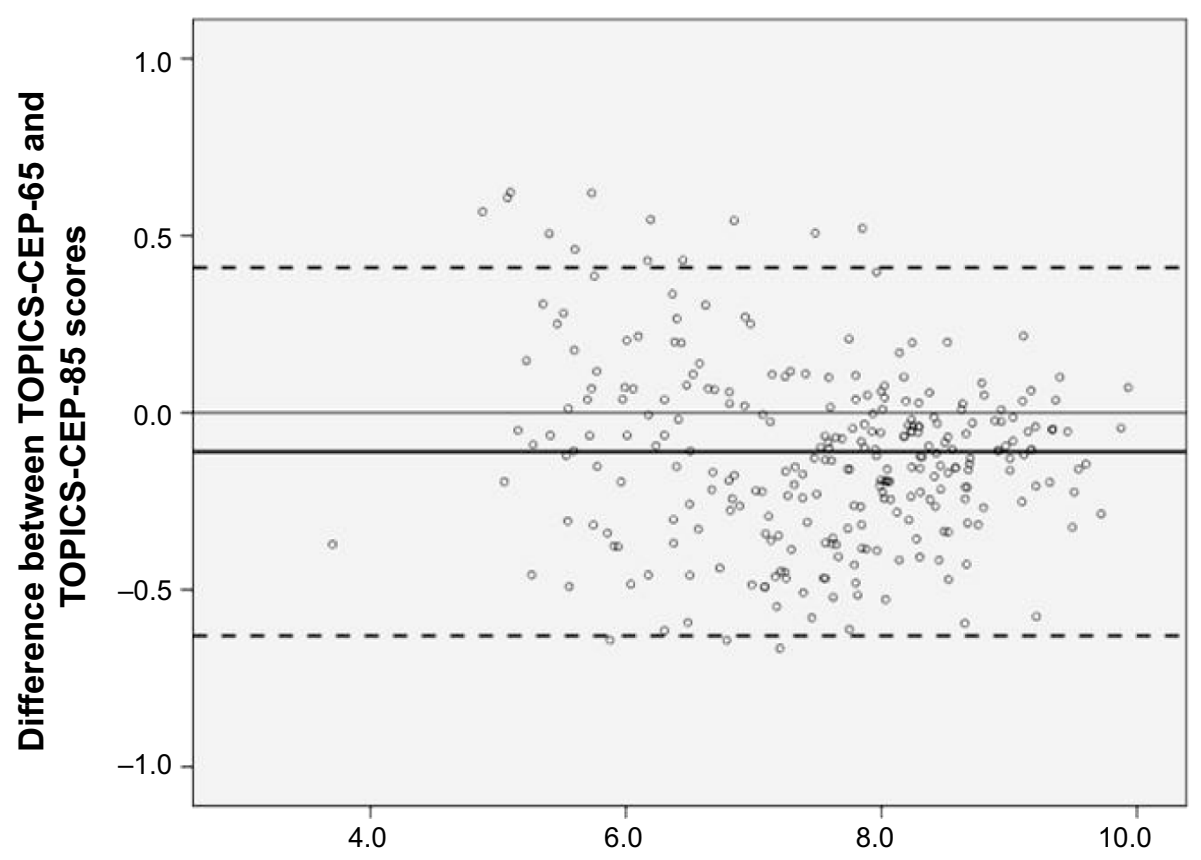

Mean of TOPICS-CEP-65 and TOPICS-CEP-85 scores

Figure 2 Bland-Altman plot of TOPIC-CEP scores of 65-year-old versus 85-year-old persons.

Notes: Bland-Altman plot: difference between CEP scores of the vignette cases based on preferences of 65-year-old versus 85-year-old persons plotted against their average. Bold solid line represents the average difference between methods; dotted lines represent the $95 \%$ confidence limits.

Abbreviations: QOL, quality of life; TOPICS-CEP-65, The Older Persons and Informal Caregivers Survey - Composite Endpoint scores for 65-year-old persons; TOPICSCEP-85, The Older Persons and Informal Caregivers Survey - Composite Endpoint scores for 85-year-old persons.

The Bland-Altman plot shows that TOPICS-CEP scores based on the health-state preferences of 65 -year-old persons are systematically different from those based on the preferences of 85 -year-old persons. Even though $95 \%$ of the observations were located between the limits of agreement, it is questionable whether the range of these limits was not too wide. In our opinion, the limits of agreement was relatively big (1.04 points on a 6.61 range); therefore, we proposed to alter the limits of agreement. After alteration, fewer than $95 \%$ of the observations were located between the two levels, suggesting low agreement when TOPICS-CEP-65 and TOPICS-CEP-85 scores are compared.

Preferences are known to vary by persons' own experiences. ${ }^{11-13}$ This could possibly explain the influence of our raters' age on the TOPICS-CEP preference weights. It is well known that prevalence of chronic conditions and multimorbidity is higher in older age groups and that functional limitation increases with age. ${ }^{16,17}$ Hence, the older the rater, the higher the chance this person has experience with having one or more chronic conditions and functional limitations. The discrepancy in preference weights between younger and older persons may be explained by the reference point or framework from which people think. With multimorbidity being the norm rather than the exception for older persons, they may have accepted it as part of the normal aging process and adapted to this deterioration by altering their expectations and norms, adapting to their situation, and adjusting their standards of "good" health accordingly. ${ }^{18}$ Moreover, older persons who have experienced functional decline may understand the full impact of functional limitations even better than those who have not. Functional limitations does not only mean one needs daily support, but it also means loss of independence, autonomy, and dignity in some cases. ${ }^{19}$

\section{Benefits and limitations of the study}

The benefit of this study is to give more insight into the influence of raters' age on individual health domains as well as overall value. However, we need to contextualize the findings in light of some limitations. Even though we have explored the influence of raters' age, other characteristics may have influenced the TOPICS-CEP preference weights. The influence of age might have been biased by the omission of other variables, such as socioeconomic status and multimorbidity. ${ }^{20}$ However, because the raters were recruited in both urban and more-rural parts of the Netherlands, and because the number of morbidities within our study sample was equally distributed, we do not expect socioeconomic status and multimorbidity to have influenced our findings. Additionally, we have explored whether observed characteristics such as raters' role as informal caregiver (previous study) and raters' 
sex, self-perceived health state, and self-perceived QOL influenced our results, which was not the case (analyses not shown). Moreover, even though we have established that the preference weights of TOPICS-CEP need to be adjusted for the age distribution of the Dutch population aged 65 years and older, further investigations are necessary to assess the reliability, validity, and generalizability of TOPICS-CEP.

\section{Benefits and limitations of TOPICS-CEP}

The benefits of using TOPICS-MDS (questionnaire) and TOPICS-CEP (scores) are that a range of important endpoints will be collected and incorporated in a single metric, which can index the overall impact of interventions in a standardized way. Consequently, establishing the value of interventions will be easier and more objective, and investigators do not need to make arbitrary choices when deciding which measure to elect as primary outcome measure. Moreover, TOPICSCEP establishes a link between various health domains and a measurement of general wellbeing.

The limitations of using TOPICS-CEP are that the scores can be difficult to interpret, as the observed effect of TOPICS-CEP does not necessarily reflect the effects of the single components. Incorrect interpretation may result in overestimation of the effects of an intervention. Therefore, we recommend reporting the effects of an intervention not only on TOPICS-CEP scores but also on the eight components separately. Further, TOPICS-CEP's content has not yet been mapped to the International Classification of Functioning, Disability, and Health (ICF), which is a classification framework of health and health-related conditions developed by the World Health Organization that aims at providing a unified and standardized language for describing and classifying health domains and health-related states, thus providing a common framework for the development of outcome measures. ${ }^{21}$ To compare TOPICS-CEP results with results obtained by means of instruments that have been mapped to ICF categories, further investigation is necessary to link TOPICS-CEP components to ICF categories.

\section{Summary}

This current study provides evidence that the relative weights of health domains vary by the age of the raters who assessed the described health states; the older olds preferred functional independence while the younger olds preferred less morbidity. These variations imply that the preference weights that were obtained in our previous study and were used to establish TOPICS-CEP are a result of our random selection of participants. Therefore, we adjusted the preference weights of TOPICS-CEP for the age distribution of the Dutch population aged 65 years and older. These weights can be found in TOPICS-CEP guideline, which is available online or in Table S2. ${ }^{8}$ To our knowledge, TOPICS-CEP is the first generic composite endpoint in geriatric care based on health valuations of the Dutch older population aged 65 years and older.

\section{Conclusion}

Researchers examining the effectiveness of health care interventions in elderly care need to consider the discrepancies between the health-state preferences of younger and older persons when choosing or developing outcome measures. Failure to recognize these discrepancies may lead to incorrect interpretation of the findings and consequently the establishment of inappropriate health care policies. Furthermore, in clinical decision making, health care professionals need to be aware of this discrepancy as well. Therefore, we highly recommend shared decision making in geriatric care.

\section{Acknowledgments}

We are very grateful to all participants. In addition, we would like to thank Wim Lemmens for his technical support and George Borm for his advice on study design. This work was supported by a grant from The Dutch National Care for the Elderly Program, coordinated and sponsored by ZonMw, Organization for Health Research and Development, the Netherlands (grant number 60-6190098-302).

\section{Author contributions}

All authors made substantial contributions to data generation and analysis, drafting or critical revision of the manuscript, and approval for the final version to be published.

\section{Disclosure}

The authors report no conflicts of interest in this work.

\section{References}

1. Fried LP, Ferrucci L, Darer J, Williamson JD, Anderson G. Untangling the concepts of disability, frailty, and comorbidity: implications for improved targeting and care. J Gerontol A Biol Sci Med Sci. 2004;59(3): 255-263.

2. Lutomski JE, Baars MA, Schalk BW, et al; TOPICS-MDS Consortium. The development of the Older Persons and Informal Caregivers Survey Minimum DataSet (TOPICS-MDS): a large-scale data sharing initiative. PLoS One. 2013;8(12):e81673.

3. Hofman CS, Makai P, Boter H, et al. Establishing a composite endpoint for measuring the effectiveness of geriatric interventions based on older persons' and informal caregivers' preference weights: a vignette study. BMC Geriatr. 2014;14:51. 
4. Lokale en Nationale Monitor Gezondheid. Indicatoren voor de monitor gezohdheid ouderen [Indicators to monitor health in the elderly] [webpage on the Internet]. Bilthoven, the Netherlands: Rijksinstituut voor Volksgezondheid en Milieu; 2005. Available from: https://www. monitorgezondheid.nl/gezondheidindicatoren.aspx. Accessed May 15, 2013. Dutch

5. Laan W, Zuithoff NP, Drubbel I, et al. Validity and reliability of the Katz-15 scale to measure unfavorable health outcomes in communitydwelling older people. J Nutr Health Aging. 2014;18(9):848-854.

6. Hays RD, Morales LS. The RAND-36 measure of health-related quality of life. Ann Med. 2001;33(5):350-357.

7. Krabbe PF, Stouthard ME, Essink-Bot ML, Bonsel GJ. The effect of adding a cognitive dimension to the EuroQol multiattribute health-status classification system. J Clin Epidemiol. 1999;52(4):293-301.

8. Hofman C, Melis R, Donders R, Makai P, OldeRikkert M. TOPICSCEP: A Composite Endpoint used for Relative Effectiveness Assessment in Elderly Care. Guidelines version 1.1. Nijmegen, the Netherlands: TOPICS-MDS; 2014. Available from: http://topics-mds.eu/wp-content/ uploads/2014/03/TOPICS-CEP-Guidelines-Version-1.1.pdf. Accessed April 14, 2015

9. Dolan P. Effect of age on health state valuations. J Health Serv Res Policy. 2000;5(1):17-21.

10. Wittenberg E, Halpern E, Divi N, Prosser LA, Araki SS, Weeks JC. The effect of age, race and gender on preference scores for hypothetical health states. Qual Life Res. 2006;15(4):645-653.

11. Dolan P, Roberts J. To what extent can we explain time trade-off values from other information about respondents? Soc Sci Med. 2002; 54(6):919-929.

12. Kind P, Dolan P. The effect of past and present illness experience on the valuations of health states. Med Care. 1995;33(4 Suppl) SA255-SA263.

13. Wittenberg E, Winer EP, Weeks JC. Patient utilities for advanced cancer: effect of current health on values. Med Care. 2005;43(2):173-181.
14. The Older Persons and Informal Caregiver Survey (TOPICS-MDS) Questionnaire: Care Receiver, Baseline. Nijmegen, the Netherlands: TOPICS-MDS; 2015. Available from: http://topics-mds.eu/wp-content/ uploads/2014/03/Baseline-Questionnaire_Participant.pdf. Accessed November 11, 2013.

15. The Older Persons and Informal Caregiver Survey (TOPICS-MDS). Questionnaire: Care Giver, Baseline. Nijmegen, the Netherlands: TOPICS-MDS; 2015. Available from: http://topics-mds.nl/wordpress/ wp-content/uploads/2013/09/Baseline-Questionnaire_Caregiver.pdf. Accessed October 8, 2013.

16. Nationaal Kompas Volksgezondheid. Lichamelijk functioneren: Hoeveel mensen hebben beperkingen? [webpage on the Internet]. Bilthoven, the Netherlands: Rijksinstituut voor Volksgezondheid en Milieu; 2014. Available from: http://www.nationaalkompas.nl/gezondheid-en-ziekte/ functioneren-en-kwaliteit-van-leven/lichamelijk-functioneren/hoeveelmensen-hebben-beperkingen/. Accessed October 8, 2013. Dutch.

17. van Oostrom SH, Picavet HS, van Gelder BM, et al. Multimorbiditeit en comorbiditeit in de Nederlandse bevolking: gegevens van huisartsenpraktijken [Multimorbidity and comorbidity in the Dutch population data from general practices]. Ned Tijdschr Geneeskd. 2011;155:A3193. Dutch.

18. Löffler C, Kaduszkiewicz H, Stolzenbach CO, et al. Coping with multimorbidity in old age - a qualitative study. BMC Fam Pract. 2012; $13: 45$.

19. Woolhead G, Calnan M, Dieppe P, Tadd W. Dignity in older age: what do older people in the United Kingdom think? Age Ageing. 2004;33(2): $165-170$.

20. Fried TR, McGraw S, Agostini JV, Tinetti ME. Views of older persons with multiple morbidities on competing outcomes and clinical decisionmaking. J Am Geriatr Soc. 2008;56(10):1839-1844.

21. World Health Organization. International Classification of Functioning, Disability and Health (ICF). Geneva, Switzerland: World Health Organization; 2001. 


\section{Supplementary materials}

Table SI The health outcome domains, their preference weights, items per component, and levels per item

\begin{tabular}{|c|c|c|c|}
\hline Outcome domains & Preference weights & Vignette items & Outcomes (levels) \\
\hline $\begin{array}{l}\text { Morbidity (local and national } \\
\text { health monitor) } \\
\text { van Oostrom et al' }\end{array}$ & 0.13 & $\begin{array}{l}\text { Presence of: dementia; depression; } \\
\text { incontinence; stroke, CVA or TIA; } \\
\text { hip fracture; panic or anxiety disorder; } \\
\text { dizziness with falling; vision disorder; } \\
\text { asthma; osteoporosis; diabetes; arthritis; } \\
\text { heart failure; form of cancer; complaints due } \\
\text { to benign enlarged prostate; fracture other } \\
\text { than hip fracture; hearing disorder }\end{array}$ & $\begin{array}{l}\text { Number of diseases } \\
\text { present; counting the } \\
\text { number of health items } \\
\text { "Present" } \\
\text { Range: } 0-17\end{array}$ \\
\hline $\begin{array}{l}\text { Functional limitations } \\
\text { (modified KATZ-ADL Index) } \\
\text { Kind and Dolan }{ }^{2}\end{array}$ & 0.12 & $\begin{array}{l}\text { Needing help with: brushing hair; going } \\
\text { to the toilet; taking medication; sitting down } \\
\text { and getting up from chair; getting dressed; } \\
\text { traveling; handling finances; grocery } \\
\text { shopping; walking about; taking a bath } \\
\text { or shower; housekeeping; preparing a } \\
\text { meal; eating; using the telephone }\end{array}$ & $\begin{array}{l}\text { Number of limitations in } \\
\text { (I)ADL; counting the number } \\
\text { of physical functioning items } \\
\text { "Help needed" } \\
\text { Range: } 0-15\end{array}$ \\
\hline $\begin{array}{l}\text { Emotional wellbeing (RAND-36, } \\
\text { mental health subscale) } \\
\text { Wittenberg et al }{ }^{3}\end{array}$ & 0.03 & $\begin{array}{l}\text { Feeling down; feeling blue; feeling } \\
\text { nervous; feeling happy; feeling calm }\end{array}$ & $\begin{array}{l}\text { Raw mental health score; } \\
\text { Calculating the raw score } \\
\text { of the five mental health items, } \\
\text { each ranging from I-6 } \\
\text { (always - never) } \\
\text { Range: } 5-30\end{array}$ \\
\hline $\begin{array}{l}\text { Pain experience (single-item } \\
\text { EQ-5D+C) } \\
\text { Löffler et al }{ }^{4}\end{array}$ & 0.03 & Pain experience & $\begin{array}{l}\text { I have no pain } \\
\text { I have moderate pain } \\
\text { I have very severe pain }\end{array}$ \\
\hline $\begin{array}{l}\text { Cognitive functioning } \\
\text { (single-item EQ-5D+C) } \\
\text { Löffler et al }{ }^{4}\end{array}$ & 0.14 & Cognitive problems & $\begin{array}{l}\text { I have no problems with my } \\
\text { memory, attention and } \\
\text { thinking } \\
\text { I have some problems with my } \\
\text { memory, attention and } \\
\text { thinking } \\
\text { I have severe problems with } \\
\text { my memory, attention and } \\
\text { thinking }\end{array}$ \\
\hline $\begin{array}{l}\text { Social functioning } \\
\text { (single-item RAND-36) } \\
\text { Wittenberg et } \mathrm{al}^{3}\end{array}$ & 0.01 & $\begin{array}{l}\text { Social activities hampered by physical } \\
\text { health or emotional problems }\end{array}$ & $\begin{array}{l}\text { Never } \\
\text { Rarely } \\
\text { Sometimes } \\
\text { Mostly } \\
\text { Continuously }\end{array}$ \\
\hline $\begin{array}{l}\text { Self-perceived health } \\
\text { (single item, RAND-36) } \\
\text { Wittenberg et } \text { al }^{3}\end{array}$ & 0.17 & Self-perceived health in general & $\begin{array}{l}\text { Excellent } \\
\text { Very good } \\
\text { Good } \\
\text { Reasonable } \\
\text { Poor }\end{array}$ \\
\hline $\begin{array}{l}\text { Satisfaction with quality of life } \\
\text { (single item formed using phrasing } \\
\text { similar to self-perceived health } \\
\text { question, RAND-36) } \\
\text { Wittenberg et } \text { al }^{3}\end{array}$ & 0.02 & Self-perceived QOL in general & $\begin{array}{l}\text { Excellent } \\
\text { Very good } \\
\text { Good } \\
\text { Reasonable } \\
\text { Poor }\end{array}$ \\
\hline
\end{tabular}

Abbreviations: $A D L$, activities of daily living; CVA, cerebrovascular accident; (I)ADL, instrumental activities of daily living; $Q O L$, quality of life; TIA, transient ischemic attack. 
Table S2 The original TOPICS-CEP components' weights and the weights adjusted for the age distribution of older persons ( $\geq 65$ years old) in the Netherlands

\begin{tabular}{lll}
\hline & Original TOPICS-CEP weights & Adjusted TOPICS-CEP weights \\
\hline Intercept & 9.03 & 9.00 \\
Morbidities & -0.14 & -0.13 \\
Functional limitations & -0.12 & -0.12 \\
Emotional wellbeing & -0.04 & -0.03 \\
Pain experience & -0.04 & -0.03 \\
Cognitive problems & -0.13 & -0.14 \\
Social functioning & -0.01 & -0.01 \\
Self-perceived health & -0.16 & -0.17 \\
Self-perceived QOL & -0.03 & -0.02 \\
\hline
\end{tabular}

Abbreviations: QOL, quality of life; TOPICS-CEP, The Older Persons and Informal Caregivers Survey - Composite Endpoint score.

\section{References}

1. Lokale en Nationale Monitor Gezondheid. Indicatoren voor de monitor gezohdheid ouderen [Indicators to monitor health in the elderly] [webpage on the Internet]. Bilthoven, the Netherlands: Rijksinstituut voor Volksgezondheid en Milieu; 2005. Available from: https://www. monitorgezondheid.n1/gezondheidindicatoren.aspx. Accessed May 15, 2013. Dutch.

2. Laan W, Zuithoff NP, Drubbel I, et al. Validity and reliability of the Katz-15 scale to measure unfavorable health outcomes in communitydwelling older people. J Nutr Health Aging. 2014;18(9):848-854.
3. Hays RD, Morales LS. The RAND-36 measure of health-related quality of life. Ann Med. 2001;33(5):350-357.

4. Krabbe PF, Stouthard ME, Essink-Bot ML, Bonsel GJ. The effect of adding a cognitive dimension to the EuroQol multiattribute health-status classification system. J Clin Epidemiol. 1999;52(4):293-301.
Clinical Interventions in Aging

\section{Publish your work in this journal}

Clinical Interventions in Aging is an international, peer-reviewed journal focusing on evidence-based reports on the value or lack thereof of treatments intended to prevent or delay the onset of maladaptive correlates of aging in human beings. This journal is indexed on PubMed Central, MedLine,

\section{Dovepress}

CAS, Scopus and the Elsevier Bibliographic databases. The manuscript management system is completely online and includes a very quick and fair peer-review system, which is all easy to use. Visit http://www.dovepress. com/testimonials.php to read real quotes from published authors. 